\title{
Factors Related to Duration of Dialysis Among Sudanese Patients on Hemodialysis at Gezira Hospital for Renal Diseases and Surgery, Gezira State, Sudan; 2018
}

\author{
Taha Ahmed Elmukashfi Elsheikh ${ }^{1, *}$, Mohamed Abdel Salam Nurein ${ }^{2}$, Mustafa Omran Mansour ${ }^{3}$ \\ ${ }^{1}$ Department of Community Medicine, University of Khartoum, Khartoum, Sudan \\ ${ }^{2}$ Department of Anatomy, University of Karrari, Khartoum, Sudan \\ ${ }^{3}$ Department of Urology, University of Gezira, Wadmedani, Sudan
}

Email address:

tahamukashfi@hotmail.com (T. A. E. Elsheikh), tahamukashfi@uofk.edu (T. A. E. Elsheikh)

${ }^{*}$ Corresponding author

\section{To cite this article:}

Taha Ahmed Elmukashfi Elsheikh, Mohamed Abdel Salam Nurein, Mustafa Omran Mansour. Factors Related to Duration of Dialysis Among Sudanese Patients on Hemodialysis at Gezira Hospital for Renal Diseases and Surgery, Gezira State, Sudan; 2018. European Journal of Preventive Medicine. Vol. 7, No. 5, 2019, pp. 89-94. doi: 10.11648/j.ejpm.20190705.13

Received: September 11, 2019; Accepted: October 4, 2019; Published: October 15, 2019

\begin{abstract}
End stage renal disease constitutes a public health problem globally. One of methods of solution of this problem is hemodialysis. To determine factors related to duration of hemodialysis among Sudanese Patients. It was a cross-sectional survey. Fifty Sudanese Patients on regular hemodialysis at Gezira Hospital for Renal Diseases \& Surgery, Gezira State, Sudan; were selected. Independent variables were age, gender, marital status, level of education, occupation, presence and types of congenital anomalies of urinary system. Dependent variable was hemodialysis. Investigation was done using structured questionnaire. Data was analyzed using SPSS version 21. P-value $\leq 0.05$ was considered statistically significant. Age range was 19 - 70 years. Male gender was predominant (62\%) among study population. Generally duration of hemodialysis is higher among male. Sixty six percent of respondents were married. There was no statistical association between marital status and duration of hemodialysis. Thirty eight percent were graduated from secondary school, university, and postgraduate studies. Majority of the rest were either illiterateor graduated from Holly Quran School (Khalwa), or primary school. About 78\% of study population either non-employed or from low economical class. There was strong statistical association between occupation and duration of hemodialysis. Rate of congenital anomalies was $12 \%$. There was statistical relationship between both presence and types of congenital anomalies of renal system and duration of hemodialysis among study population. Economically active age group was more affected than others. Duration of hemodialysis was higher among male. Un-married respondents were more vulnerable than married groups. Duration of hemodialysis was longer among respondents with low socioeconomic status and among respondents having congenital anomalies of renal system. Screening for presence of congenital anomalies of renal system among general population may be of great help.
\end{abstract}

Keywords: Duration of Hemodialysis, ESRD, Sudanese Patients, Gezira State

\section{Introduction}

Globally, the rate of CKD is about $5 \%-10 \%$. The hemodialysis used to be carried out in order to restore the kidney function and to maintain normal electrolytes concentration together with fluid balance [1]. Chronic diseases constitute a public health problem allover the world. ESRD is one of the components of this problem. The average magnitude of this problem globally is about 465 per 1 million [2]. Knowledge about factors related to end-stage renal disease is highly needed by nephrologists for planning preventive measures [3].

It is reported among patients on heamodialysis in Iran that the mean duration of dialysis is 34.03 months; and old age, 
level of education, employment, and income affect the quality of life among them. So, educated people can cope with this disease more than others [2]. In a study done in Lahore, Pakistan, the male constitutes $71.2 \%$ of the study population, which are patients on heamodialysis; and the duration of dialysis is inversely related to quality of life; i.e. it decreases as the quality of life improved [4]. The rate of withdrawal of dialysis is higher among women compared to men, and older patients compare to younger [5]. Male gender is negatively associated with withdrawal of heamodialysis. There is no relation between withdrawal of hemodialysis and income, level of education, employment, and marital status [5]. A study carried out among patients on heamodialysis in Saudi, revealed that the mean age of the respondents is 51.7 years $( \pm 15.4)$. The level of satisfaction is affected by gender, duration on dialysis, educational level, and standard of care given. So, gender type, and educational level together will affect the duration of dialysis [6]. In Palestine, there is a significant negative association of outcome and duration of hemodialysis with age, level of education, and female gender [7]. In another study carried in Palestine there is a relation between worsening of health related quality of life among patients on heamodialysis and older age together with low level of education. So, the duration of dialysis may increase [8]. The last stage of the National Kidney Foundation Kidney Disease Outcomes Quality is ESRD. The global prevalence of ESRD in the last 10 years has risen steadily by $4-8 \%$ per year. Haemodialysis performed treatment modality among ESRD where about $90.6 \%$ undergoing through it [8]. The mean age of patients is $50.3 \pm 16$ years, male gender representation is $61.8 \%$, marital status rate is $74.2 \%$, unemployed rate is $79.9 \%$, and higher level of education rate (i.e. university level and above) is $44.5 \%$ [8]. Poor quality of life affects the outcome of ESRD [9]. Among Iraqi patients on hemodialysis, gender (female) and marital status are significantly statistically associated [10]. Quality of life is negatively affected by: female gender, older age, low level of education and divorced/widowed among Greece patients [11]. The outcome of ESRD is negatively affected by: female gender, increased age, un-employment, single, and decreased level of education [12]. In Ghana the male gender representation among patients on hemodialysis is $64.5 \%$ [13]. The percentage of male gender among patients on hemodialysis in Cameron is $66 \%$; the overall mean age of 47.4 years; where mean age for men is 48.9 , and for female is 44.5. So, gender and age are important factors related to ESRD [14]. The male gender is predominant (66.7\%) among chronic kidney disease patients; the mean age is $49.27 \pm 16.7$ years, rate of marriage is $70.6 \%$, level of undergraduate education is $40 \%$, rate of employment is $34 \%$, low income group represents $41.6 \%$ and middle income group represents $37.3 \%$ [15]. In Sudan, it is reported that the age is directly proportion to the requirement of dialysis. Also mortality is significantly related to increase in patient's age, plus other health problems [16]. Another study carried out in Sudan revealed that the mean age of ESRD Patients is $49 \pm 15.8$ (years) and $63.4 \%$ are male and $76.3 \%$ are unemployed. The mean duration of haemodialysis is $4.38 \pm 4.24$ (years). ESRD in Sudan affects the economically productive age group, where in many developed countries the mean age of them is generally over 60 years [17]. The vulnerable Sudanese groups for ESRD are characterized by: younger age, unmarried, and low level of education [18]. Horseshoe kidney, polycystic kidney disease, double ureter or ureteral duplication, ureteropelvic junction (UPJ) obstruction, posterior urethral valves, hypogenesis, agenesis, and kidney position are congenital anomalies of urinary system that associated with hemodialysis [3]. Congenital anomalies of urinary system represent $34-59 \%$ of chronic kidney disease (CKD) and $31 \%$ of end-stage kidney disease (ESKD) in children in USA [19]. Increased age, male gender, low level of education, and polycystic kidney disease are risk factors for hemodialysis [20].

Problem identification and Justification:

To my knowledge there is gap knowledge about factors related to duration of hemodialysis in Sudan. So, this study was conducted to determine thesefactors and their effects on the duration of hemodialysis among Sudanese Patients on hemodialysisattending Gezira Hospital for Renal Diseases \& Surgery, Gezira State, Sudan; February to April 2018. So as to help the nephrologists for planning their diagnosis and expected outcome.

Aim of the study: To determine factors related to duration of hemodialysis among Sudanese Patients with ESRD on regular hemodialysis attending Gezira Hospital for Renal Diseases \& Surgery, Gezira State, Sudan; during the period from February - April 2018.

\section{Methods}

\subsection{Study Design}

It was a cross-sectional survey.

\subsection{Study Area and Setting}

It wascarried out at Gezira Hospital for Renal Diseases\& Surgery, Gezira State, Sudan. Historically, the Kidney Department at Wadmedani Teaching Hospital is transferred to Gezira Hospital for Renal Diseases and Surgery as a specialized hospital on $18 / 2 / 2002$. It provides serves to the population of the Central and Eastern States of Sudan. It consists oftwo departments: Department of Urology and Surgery and Department of Nephrology.

\subsection{Study Populations and Sampling}

Sudanese patients with ESRD on regular hemodialysis. Fifty patients were selected.

\subsection{Variables}

\subsubsection{Independent Variables}

age, gender, marital status, level of education, occupation, presence and types of congenital anomalies of urinary system. 


\subsubsection{Dependent Variable}

Dependent variable was hemodialysis.

\subsection{Data Collection Methods and Techniques}

A structured close end questionnaire was used.

\subsection{Data Management and Analysis}

Data wasmanaged and analyzed using SPSS version 21. $C h i$-square test was used and $P$-value $\leq 0.05$ was considered statistically significant.

\subsection{Ethical Concern}

It was ethically approvedby Gezira University Ethical Board together with Gezira Hospital for Renal Diseases and Surgery, and thenconsent was taken from eachrespondents.

\section{Results}

The age range was 19 - 70 years. The mean age was 45.10 years and the Std. Deviation was 14.755. Male gender representation of the study population was $62 \%$. Regarding education $20 \%$ were illiterate, $6.0 \%$ graduated fromHolly Quran School (Khalwa), 36\% from primary school, 14\% from secondary school, 14\% from university, and 10\% had postgraduate certificate. Twenty percent were labors, $8 \%$ were farmers, $6 \%$ were employee, $2 \%$ were merchants, $4 \%$ were students, $24 \%$ were households, $2 \%$ were from medical field, $4 \%$ were non-employee, and $30 \%$ did not response to identify their occupations. Sixty six percent were married while $34 \%$ were not married. The rate of the congenital anomalies among the study population was $12 \%$; and their types were: polycystic kidney disease $(6 \%)$, uretero-pelvic junction (UPJ) obstruction - right kidney (2\%), hypo-genesis of the left kidney (2\%), and agenesis of the right kidney $(2 \%)$.

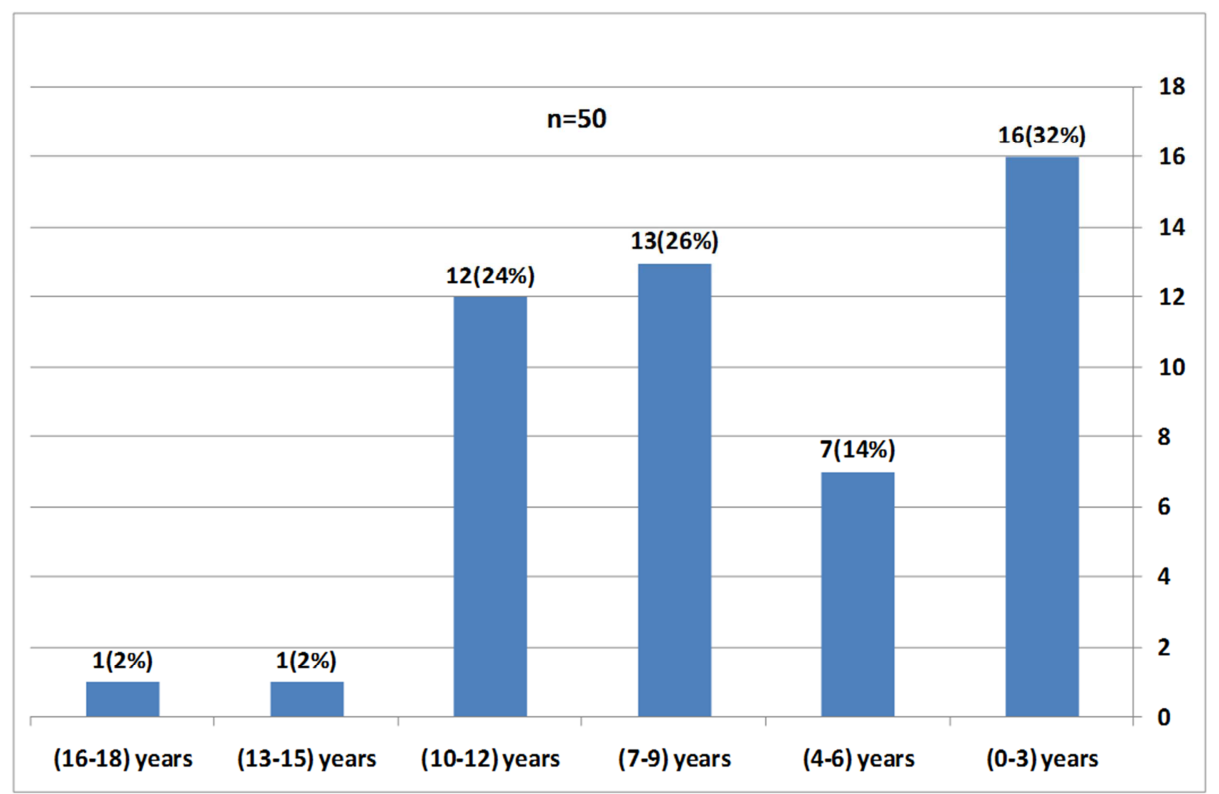

Figure 1. Duration of disease of patients on Hemodialysis at Gezira Hospital for Renal Diseases and Surgery, Gezira State, Sudan; 2018. ( $n=50)$.

The duration of the disease among the study population was (0-3 years) among 32\% of them; and 16-18 years among $2 \%$ (Figure 1).
Mean duration of the disease equals 2.56 years, Std. Deviation $=1.32727$, minimum duration $=1.00$ year, and maximum duration $=6.00$ years.

Table 1. The relation between age group and duration of disease among patients on Hemodialysis at Gezira Hospital for Renal Diseases and Surgery, Gezira State, Sudan; 2018; $(n=48)$.

\begin{tabular}{|c|c|c|c|c|c|c|c|c|}
\hline \multirow{2}{*}{ Age group (years) } & \multicolumn{6}{|c|}{ Duration of disease groups (years) } & \multirow{2}{*}{ Total } & \multirow{2}{*}{ P-value } \\
\hline & $(0-3)$ & $(4-6)$ & $(7-9)$ & $(10-12)$ & (13-15) & (16-18) & & \\
\hline$(15-25)$ & 5 & 0 & 2 & 1 & 0 & 0 & 8 & \multirow{6}{*}{0.243} \\
\hline$(26-35)$ & 1 & 0 & 0 & 2 & 0 & 1 & 4 & \\
\hline$(36-45)$ & 5 & 2 & 1 & 4 & 0 & 0 & 12 & \\
\hline$(46-55)$ & 2 & 2 & 4 & 2 & 0 & 0 & 10 & \\
\hline$(56-65)$ & 1 & 1 & 4 & 3 & 1 & 0 & 10 & \\
\hline$(66-75)$ & 2 & 1 & 1 & 0 & 0 & 0 & 4 & \\
\hline
\end{tabular}

NB. Two cases out of the total (50) did not specify their ages.

There was no statistical association between age group and duration of disease among respondents $(P$-value $=0.243)($ Table 1). 
Table 2. The relation between gender and duration of disease among patients on Hemodialysis at Gezira Hospital for Renal Diseases and Surgery, Gezira State, Sudan; 2018; $(n=50)$.

\begin{tabular}{|c|c|c|c|c|c|c|c|c|}
\hline \multirow{2}{*}{ Gender } & \multicolumn{6}{|c|}{ Duration ofdisease group (years) } & \multirow{2}{*}{ Total } & \multirow{2}{*}{$\begin{array}{l}P \text { - } \\
\text { value }\end{array}$} \\
\hline & $(0-3)$ & (4-6) & $(7-9)$ & (10-12) & (13-15) & (16-18) & & \\
\hline Male & 9 & 5 & 6 & 10 & 1 & 0 & 31 & \\
\hline Female & 7 & 2 & 7 & 2 & 0 & 1 & 19 & 0.266 \\
\hline Total & 16 & 7 & 13 & 12 & 1 & 1 & 50 & \\
\hline
\end{tabular}

Looking at Table 2 we noticed that the duration of the disease among the different duration of disease group is higher among male compare to female except among the group (16-18) years. There was no statistical association between the duration of the disease and the gender of the respondents.

Table 3. The relation between education level and duration of disease among patients on Hemodialysis at Gezira Hospital for Renal Diseases and Surgery, Gezira State, Sudan; 2018; $(n=50)$.

\begin{tabular}{llllllll}
\hline \multirow{2}{*}{ Education level } & \multicolumn{2}{l}{ Duration of disease groups (years) } & & \multicolumn{2}{c}{ T- } \\
\cline { 2 - 8 } & $\mathbf{( 0 - 3 )}$ & $\mathbf{( 4 - 6 )}$ & $\mathbf{( 7 - 9 )}$ & $\mathbf{( 1 0 - 1 2 )}$ & $\mathbf{( 1 3 - 1 5 )}$ & $\mathbf{( 1 6 - 1 8 )}$ & value \\
\hline Illiterate & 3 & 2 & 3 & 2 & 0 & 0 & 10 \\
Holly Quran School (Khalwa) & 1 & 0 & 1 & 1 & 0 & 0 & 3 \\
Primary & 7 & 1 & 3 & 6 & 1 & 0 & 18 \\
Secondary & 1 & 2 & 2 & 2 & 0 & 0 & 7 \\
Higher & 2 & 1 & 2 & 1 & 0 & 1 & 7 \\
Graduated & 2 & 1 & 2 & 0 & 0 & 0 & 5 \\
Total & 16 & 7 & 13 & 12 & 1 & 1 & 50 \\
\hline
\end{tabular}

There was no statistical association between education level and duration of disease among respondents $(P$-value $=0.934)$ (Table 3).

Table 4. The relation between occupation and duration of disease among patients on Hemodialysis at Gezira Hospital for Renal Diseases and Surgery, Gezira State, Sudan; 2018; $(n=50)$.

\begin{tabular}{|c|c|c|c|c|c|c|c|c|}
\hline \multirow{2}{*}{ Occupation } & \multicolumn{6}{|c|}{ Duration of disease groups years } & \multirow{2}{*}{ Total } & \multirow{2}{*}{$\begin{array}{l}P \text { - } \\
\text { value }\end{array}$} \\
\hline & $(0-3)$ & (4-6) & $(7-9)$ & $(10-12)$ & $(13-15)$ & $(16-18)$ & & \\
\hline Labor & 1 & 3 & 2 & 4 & 0 & 0 & 10 & \multirow{9}{*}{0.003} \\
\hline Farmer & 1 & 1 & 0 & 1 & 1 & 0 & 4 & \\
\hline Employee & 0 & 1 & 2 & 0 & 0 & 0 & 3 & \\
\hline Merchant & 0 & 0 & 1 & 0 & 0 & 0 & 1 & \\
\hline Student & 2 & 0 & 0 & 0 & 0 & 0 & 2 & \\
\hline Housewife & 4 & 2 & 6 & 0 & 0 & 0 & 12 & \\
\hline Non-employee & 1 & 0 & 0 & 0 & 0 & 1 & 2 & \\
\hline No response & 6 & 0 & 2 & 7 & 0 & 0 & 15 & \\
\hline Total & 16 & 7 & 13 & 12 & 1 & 1 & 50 & \\
\hline
\end{tabular}

There was strong statistical association between occupation and duration of disease among the study population $(P$-value $=$ 0.003) (Table 4).

Table 5. The relation between marital status and duration of disease among patients on Hemodialysis at Gezira Hospital for Renal Diseases and Surgery, Gezira State, Sudan; 2018; $(n=50)$.

\begin{tabular}{|c|c|c|c|c|c|c|c|c|}
\hline \multirow{2}{*}{ Marital status } & \multicolumn{6}{|c|}{ Duration of disease groups years } & \multirow{2}{*}{ Total } & \multirow{2}{*}{$\begin{array}{l}P- \\
\text { value }\end{array}$} \\
\hline & $(0-3)$ & (4-6) & $(7-9)$ & $(10-12)$ & $(13-15)$ & (16-18) & & \\
\hline Married & 8 & 7 & 9 & 8 & 1 & 0 & 33 & \multirow{3}{*}{0.159} \\
\hline Not married & 8 & 0 & 4 & 4 & 0 & 1 & 17 & \\
\hline Total & 16 & 7 & 13 & 12 & 1 & 1 & 50 & \\
\hline
\end{tabular}

There was no statistical association between marital status and duration of disease among respondents $(P$-value $=0.159)$ (Table 5)

Table 6. The relation between presence of congenital anomalies and duration of disease among patients on Hemodialysis at Gezira Hospital for Renal Diseases and Surgery, Gezira State, Sudan; 2018; $(n=50)$.

\begin{tabular}{|c|c|c|c|c|c|c|c|c|}
\hline \multirow{2}{*}{$\begin{array}{l}\text { presence of congenital } \\
\text { anomalies }\end{array}$} & \multicolumn{6}{|c|}{ Duration ofdisease group } & \multirow{2}{*}{ Total } & \multirow{2}{*}{ Pvalue } \\
\hline & $(0-3)$ years & (4-6) years & (7-9) years & $(10-12)$ years & (13-15) years & (16-18) years & & \\
\hline Yes & 1 & 2 & 0 & 2 & 0 & 1 & 6 & \\
\hline No & 15 & 5 & 13 & 10 & 1 & 0 & 44 & 0.037 \\
\hline Total & 16 & 7 & 13 & 12 & 1 & 1 & 50 & \\
\hline
\end{tabular}


There was statistical relationship between the presence of the congenital anomalies of the renal system and the duration of the disease among the study population, P value was (0.037); (Table 6).

Table 7. The relation between types of congenital anomalies and duration of disease among patients on Hemodialysis at Gezira Hospital for Renal Diseases and Surgery, Gezira State, Sudan; 2018; $(n=50)$.

\begin{tabular}{lllllll}
\hline \multirow{2}{*}{ Types of congenital anomalies } & \multicolumn{2}{l}{ Duration ofdisease group (years) } & & P value \\
\cline { 2 - 5 } & $\mathbf{( 0 - 3 )}$ & $\mathbf{( 4 - 6 )}$ & $\mathbf{( 7 - 9 )}$ & $\mathbf{( 1 0 - 1 2 )}$ & $\mathbf{( 1 3 - 1 5 )}$ & $\mathbf{( 1 6 - 1 8 )}$ \\
\hline Polycystic Kidney Disease & 0 & 2 & 0 & 0 & 0 & 1 \\
Ureteropelvic junction (UPJ) obstruction & 0 & 0 & 0 & 1 & 0 & 0 \\
Hypo-genesis & 1 & 0 & 0 & 0 & 0 & 0 \\
Agenesis & 0 & 0 & 0 & 1 & 0 & 1 \\
Not applicable & 15 & 5 & 13 & 10 & 1 & 0 \\
Total & 16 & 7 & 13 & 12 & 1 & 0 \\
\hline
\end{tabular}

There was statistical relationship between the types of congenital anomalies of the renal system and the duration of the disease among the study population, $P$ value was $(0.033)$; (Table 7).

\section{Discussion}

A cross sectional facility base survey was conducted among ESRD Sudanese patients on regular heamodialysis at Gezira Hospital for Renal Diseases and Surgery. A total of fiftypatients were selected.

The age range was 19 - 70 years with the mean age of 45.10 years and the Std. Deviation of 14.755. There was no statistical association between age group and duration of disease among respondents. This is similar to what is reported in USAthat age (risk increase with age) is a risk factor for heamodialysis [20], in Saudi [6] and in Sudan [17, 18]. In Palestine there is a significant statistical association between duration of hemodialysis and age $[7,8]$. The overall mean age of patients on hemodialysis in Cameron is 47.4 years [14]. The mean age is $49.27 \pm 16.7$ years among chronic kidney disease patients [15]. The vulnerable Sudanese groups for ESRD are characterized by being of younger age [18]. This is the more economically active age group. This is an indicator for the burden of such disease. So, age is an important factor related to ESRD

Male gender was predominant (62\%) among the study population. Generally the duration of the disease is higher among male compare to female. This may be due to the high incidence of the disease among males compare to females. There is no statistical association between the duration of the disease and the gender of the respondents. This finding is similar to what is reported in USA that sex (male is more than female) is a risk factor for heamodialysis [20]; in Lahore - Pakistan that $71.2 \%$ of his study population is male [4] andin Sudan [17]. In Palestine there is a significant statistical association between the duration of hemodialysis and gender [7]. Also in Palestine male gender representation among patients on hemodialysis is $61.8 \%$ [8]. Among Iraqi patients on hemodialysis, there is significant statistical association with gender [10]. In Ghana the male gender representation among patients on hemodialysis is $64.5 \%$. [13]. The percentage of male gender among patients on hemodialysis in Cameron is $66 \%$ [14]. The male gender is predominant
(66.7\%) among chronic kidney disease patients [15]. So, gender is an important factor related to ESRD.

Regarding education, only $38 \%$ were graduated from secondary school, university, and postgraduate studies. The majority of the rest were illiterate, graduated from Holly Quran School (Khalwa), and from primary school. There was no statistical association between education level and duration of disease among respondents. It is reported in Iran that educated people can cope with this disease more than others [2]. In Palestine there is a significant statistical association between the duration of hemodialysis and level of education [7]. Also in Palestine there is a relation between worsening of health related quality of life among patients on heamodialysis and low level of education. So, the duration of dialysis may increase [8]. The vulnerable Sudanese groups for ESRD are characterized by low level of education [18]. The level of undergraduate education is $40 \%$ among chronic kidney disease patients [15]. Low level of education is a risk factor for hemodialysis [20].

About $78 \%$ of our study population either non-employed or from low economical class. In our study there was strong statistical association between occupation and duration of disease among the study population. This is similar to what is reported in Sudan that $76.3 \%$ of study population isunemployed [17]. Also in Lahore - Pakistan reported that the duration of dialysis is inversely related to quality of life; i.e. it decreases as the quality of life improved. Many patients with ESRD either from low economical class or may loose their job as a result of the disease [4]. In Palestine the unemployed rate among patients on hemodialysis is $79.9 \%$ [8]. The rate of employment is $34 \%$, low income group represents $41.6 \%$ and middle income group represents $37.3 \%$ among chronic kidney disease patients [15]. So, occupation or financial situation is an important factor related to duration of hemodialysis.

Sixty six percent of our respondents were married. There was no statistical association between marital status and duration of disease among them. In comparison to other studies we found that in Palestine the marital status rate among patients on hemodialysis is 74.2\% [8]; among Iraqi patients on hemodialysis, marital status is significantly statistically associated [10]; the rate of marriage is 70.6\%among chronic kidney disease patients [15]; and the vulnerable Sudanese groups for ESRD are characterized by being un-married [18].

The rate of the congenital anomalies among the study 
population was $12 \%$; and their types were: polycystic kidney disease $(6 \%)$, uretero-pelvic junction (UPJ) obstruction right kidney ( $2 \%)$, hypo-genesis of the left kidney ( $2 \%)$, and agenesis of the right kidney (2\%). Congenital anomalies of urinary system represent $31 \%$ of end-stage kidney disease (ESKD) in children in USA [20]. Polycystic kidney disease, ureteropelvic junction (UPJ) obstruction, hypogenesis, and agenesis are congenital anomalies of urinary system that associated with hemodialysis [3]. Polycystic Kidney Disease is a risk factor for hemodialysis [20]. There was statistical relationship between both the presence and types of congenital anomalies of the renal system and the duration of the disease among the study population.

\section{Conclusion}

Economically active age group was more affected than others. Duration of hemodialysis was higher among male. Un-married respondents were more vulnerable than married groups. Duration of hemodialysis was longer among respondents with low socioeconomic status and among respondents having congenital anomalies of renal system.

\section{Recommendations}

Screening for the presence of the congenital anomalies of the renal system among the general population may be of great help. Early detection of the renal disease may help to give good prognosis.

\section{References}

[1] Ibrahim E. A. Dialysis dose in end-stage renal disease patients undergoing regular hemodialysis at Ibn-Sena and Al-Nao hospitals in Sudan. J Nephropharmacol. 2020; 9. Article History: Received: 14 September 2018. Accepted: 8 January 2019. Published online: 7 June 2019.

[2] Barzegar H., Jafari H., Charati J. Y., and Esmaeili R. Relationship Between Duration of Dialysis and Quality of Life in Hemodialysis Patients. Iran J Psychiatry Behav Sci. 2017 December; 11 (4): e6409. doi: 10.5812/ijpbs.6409.

[3] Elsharif ME \&Elsharif EG 2011] [Elsharif ME \&Elsharif EG 2011, Causes of End-Stage Renal Disease in Sudan: A SingleCenter. Saudi J Kidney Dis Transpl; 22 (2): 373-376.

[4] Anees et al. Dialysis-Related Factors Affecting Quality of Life in Patients on Hemodialysis. IJKD 2011; 5: 9-14.

[5] Qazi H. A., Chen H. and Zhu M. Factors influencing dialysis withdrawal: a scoping review. BMC Nephrology (2018) 19: 96https://doi.org/10.1186/s12882-018-0894-5

[6] Al Eissa M., et al. Factors Affecting Hemodialysis Patients' Satisfaction with Their Dialysis Therapy. International Journal of Nephrology Volume 2010, Article ID 342901, 5 pages, doi: $10.4061 / 2010 / 342901$.

[7] Zyoud et al. Factors affecting quality of life in patients on haemodialysis: a cross-sectional study from Palestine. BMC Nephrology (2016) 17: 44DOI 10.1186/s12882-016-0257-z
[8] Mousa et al. Dialysis-related factors affecting selfefficacy and quality of life in patients on haemodialysis: a cross-sectional study from Palestine. Renal Replacement Therapy (2018) 4: $21 \mathrm{https} / /$ doi.org/10.1186/s41100-018-0162-y

[9] Chartier et al. Prevalence, socio-demographic characteristics, and comorbid health conditions in pre-dialysis chronic kidney disease: results from the Manitoba chronic kidney disease cohort. BMC Nephrology (2018) 19: 255. https://doi.org/10.1186/s12882-018-1058-3.

[10] Hamody A. T., Kareem A. K., Al-Yasri A. S., Sh. Ali A. A. Depression in Iraqi Hemodialysis Patients. Arab Journal of Nephrology and Transplantation. 2013 Sep; 6 (3): 169-72.

[11] Theofilou P. A. The Impact of Sociodemographic and Psychological Variables on Quality of Life in Patients With Renal Disease: Findings of a Cross-Sectional Study in Greece. World J NephrolUrol • 2012; 1 (4-5): 101-106.

[12] Theofilou P. Depression and Anxiety in Patients with Chronic Renal Failure: The Effect of Sociodemographic Characteristics. International Journal of Nephrology, Volume 2011, Article ID 514070, 6 pages. doi: 10.4061/2011/514070.

[13] Amoako Y. A., Laryea D. O., Bedu-Addo G., Andoh H., Awuku Y. A. Clinical and demographic characteristics of chronic kidney disease patients in a tertiary facility in Ghana. Pan African Medical Journal. 2014; 18: 274 doi: 10.11604/pamj.2014.18.274.4192. This article is available online at: http://www.panafrican-medjournal.com/content/article/18/274/full/.

[14] Halle M. P., Takongue C., Kengne A. P., Kaze F. F. and Ngu K. B. Epidemiological profile of patients with end stage renal disease in a referral hospital in Cameroon. Halle et al. BMC Nephrology (2015) 16: 59. DOI 10.1186/s12882-015-0044-2.

[15] Bapat U., Nayak S. G., Kedleya P. G., Gokulnath. Demographics and Social Factors Associated with Acceptance of Treatment in Patients with Chronic Kidney Disease. Saudi J Kidney Dis Transpl 2008; 19 (1): 132-136.

[16] Osman M., et al. Pattern and outcome of acute kidney injury among Sudanese adults admitted to a tertiary level hospital: a retrospective cohort study. Pan African Medical Journal. 2017; 28: 90 doi: 10.11604/pamj.2017.28.90.11054. This article is available online at: http://www.panafrican-medjournal.com/content/article/28/90/full/

[17] Banaga et al. Causes of end stage renal failure among haemodialysis patients in Khartoum State/Sudan. BMC Res Notes (2015) 8: 502. DOI 10.1186/s13104-015-1509-x.

[18] Awadalla A. W.; Ohaeri J. U.; Al-Awadi S. A.; and Tawfiq A. M. Diabetes Mellitus Patients' Family Caregivers' Subjective Quality of Life. JOURNAL OF THE NATIONAL MEDICAL ASSOCIATION VOL. 98, NO. 5, MAY 2006727.

[19] Yosypiv IV 2012, Congenital Anomalies of the Kidney and Urinary Tract: A Genetic Disorder? International Journal of Nephrology, Volume 2012, Article ID 909083, 10 pages, https://doi.org/10.1155/2012/909083

[20] EBSCO 2016, Chronic kidney disease (CKD) in adults, viewed 4 October 2016 , http://www.dynamed.com/topics/dmp AN T115336] 